\title{
El escultismo católico como respuesta educativa
}

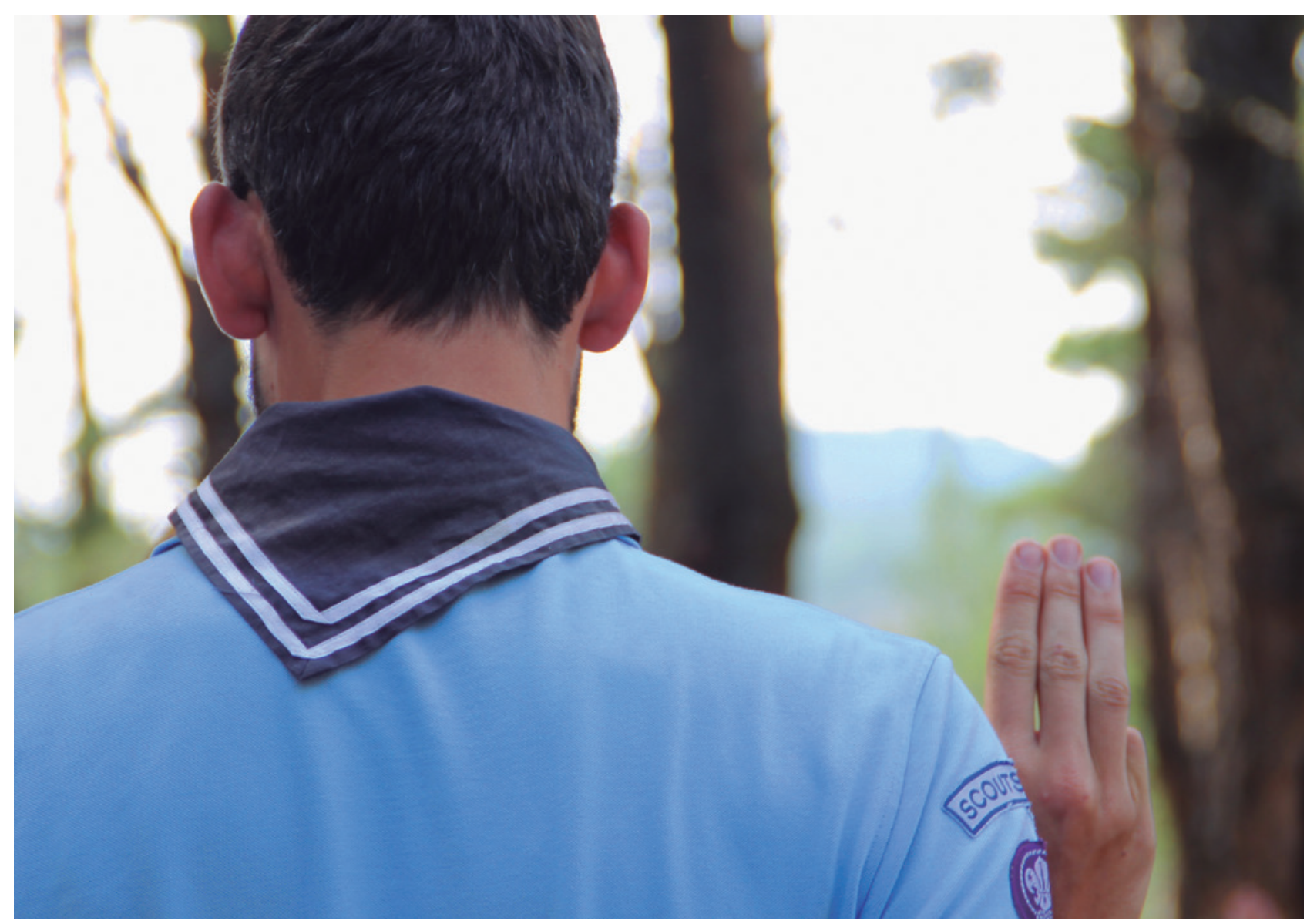

El Movimiento Scout Católico se propone como la respuesta educativa a los niños y jóvenes de la sociedad española bajo los valores de Jesús de Nazaret como ejemplo de vida. Hoy en día

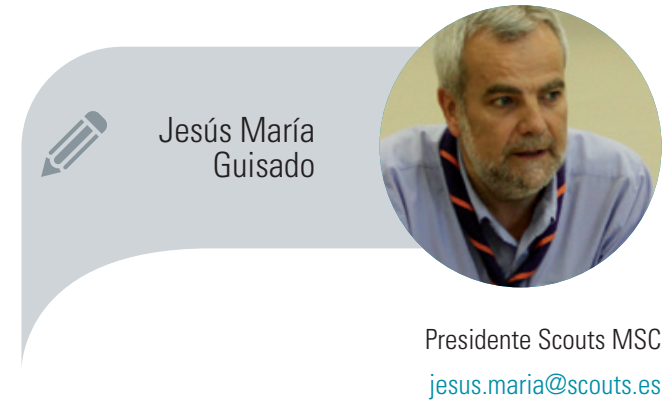
somos, con gran diferencia, el movimiento de infancia y juventud que tiene más miembros en la Iglesia Española. 
Movimiento Scout Católico, propuesta educativa en el ocio y tiempo libre

El Movimiento Scout Católico responde en gran parte a que los niños y jóvenes de la sociedad española necesitan momentos de ocio y tiempo libre, pero que además los forma en un entorno donde los valores cristianos están por encima de todo.

La propuesta educativa. La Misión de MSC (Movimiento Scout Católico) es educar a los niños y jóvenes para que desempeñen un papel activo en la sociedad para construir un mundo mejor.

En Scouts MSC disponemos de una propuesta educativa al alcance de todos los niños y jóvenes de España, especialmente de aquellos que tienen más dificultades para acceder a la educación no formal. La razón de ser del movimiento es facilitar la propuesta educativa del escultismo católico, los invitamos a asumir el protagonismo de su propio proceso de desarrollo personal para ser mejores personas.

Scouts MSC quiere responder a las expectativas y necesidades actuales de niños y jóvenes de España, a tenor de sus características individuales, enmarcado en el contexto social y articulado a través del método scout.

Actualmente somos casi 30.000 scouts católicos activos en España, somos un movimiento de Iglesia y pertenecemos directamente a la Conferencia Episcopal Española. Hoy en día somos, con gran diferencia, el movimiento de infancia y juventud que tiene más miembros en la Iglesia española.

\section{¿En qué consiste nuestro movimiento?}

Los niños y jóvenes (scouts) que forman parte del movimiento tienen derecho a disfrutar íntegra y completamente su propuesta educativa, invitamos a todos a ser personas responsables y felices, miembros activos de las comunidades de las que forman parte y cristianos comprometidos.

Cada scout es el protagonista del escultismo y el principal agente educativo del movimiento. El escultismo se fundamenta en la capacidad de los niños y

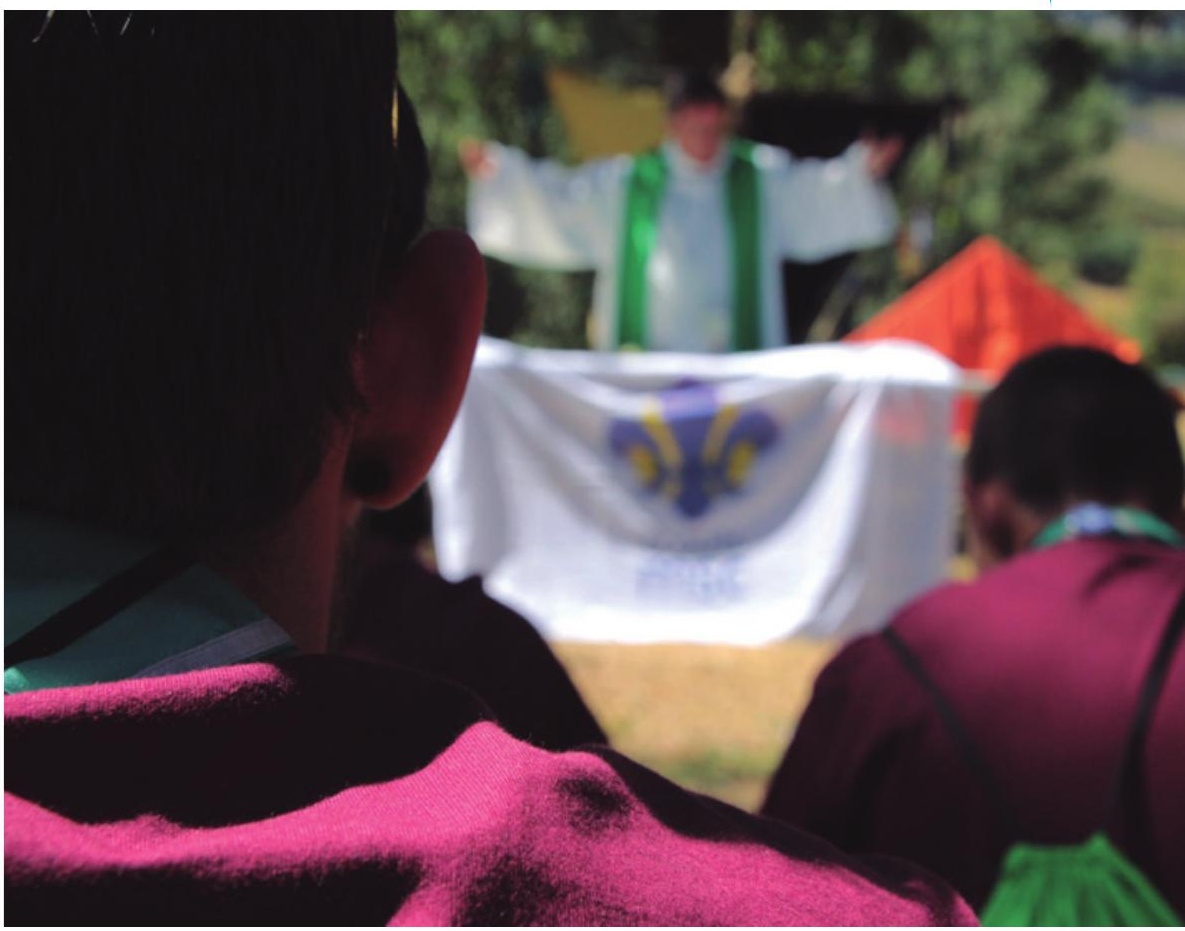

El escultismo calólico aporta un nuevo sentido a

$$
\text { la propuesta scoul, invitando a que el proyecto }
$$

personal de vida se desarrolle desde la

\section{perspectiva completamente nueva que nace del encuentro con Jesucristo}

jóvenes de responsabilizarse y hacerse verdaderos protagonistas de su proceso de crecimiento personal y en la confianza que los demás agentes educativos depositan en ellos.

Para que el scout sea verdaderamente protagonista, en Scouts MSC le proponemos un itinerario de progreso personalizado, único, coherente y transversal en su paso por las ramas (etapas scouts).

El movimiento es también un buen lugar para que otros niños y jóvenes y sus respectivas familias entren en contacto por primera vez con el Evangelio, y para que muchos niños, jóvenes y familias se reencuentren con la Iglesia después de pasar un tiempo alejados de ella. Por ello, el escultismo católico es una herramienta de gran utilidad al servicio de la Nueva Evangelización.

La acción del movimiento se desarrolla en comunión con nuestras Iglesias 


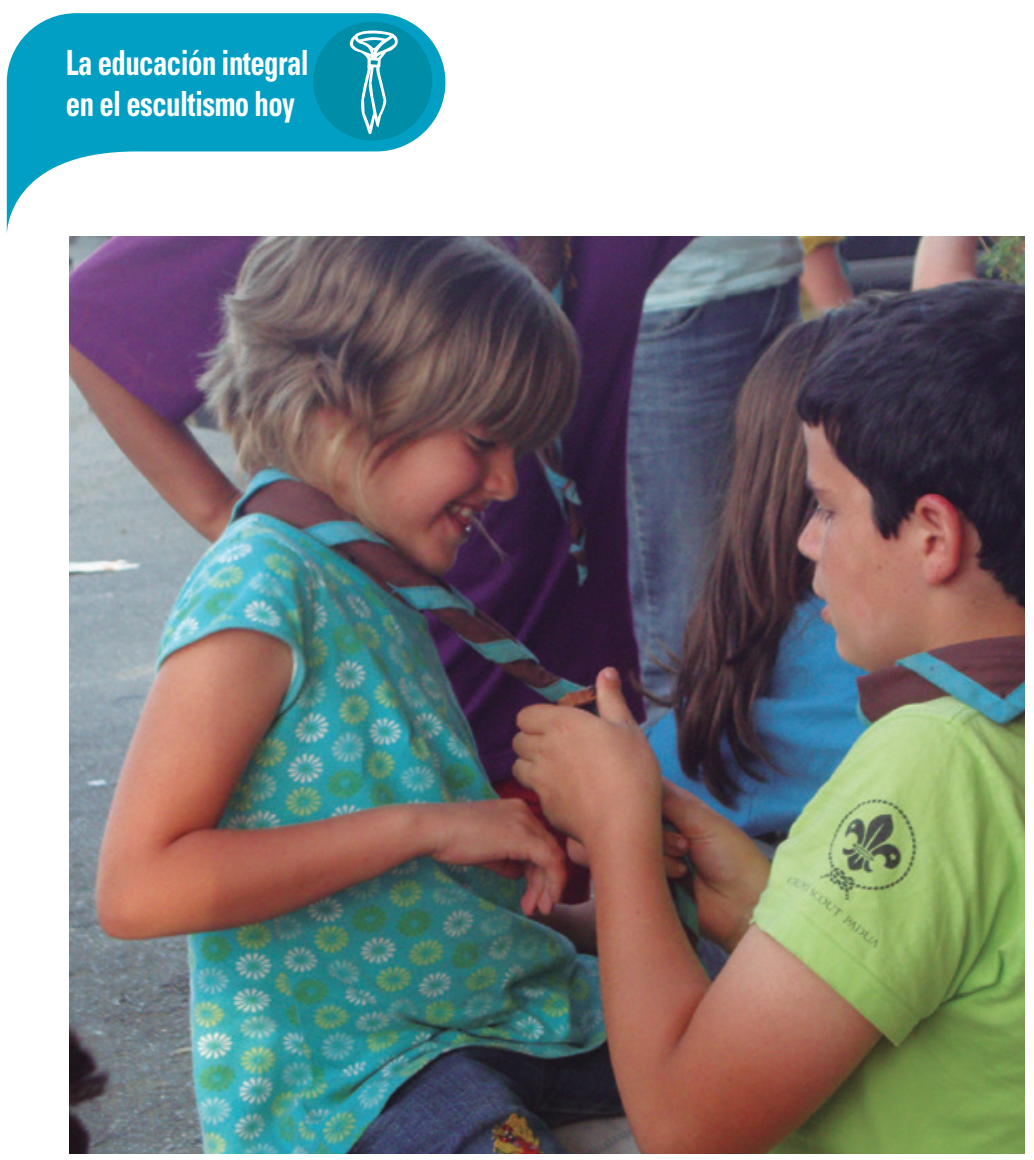

Diocesanas y en estrecha coordinación con las congregaciones religiosas, parroquias, y centros educativos católicos en los que se lleva a cabo el escultismo.

El escultismo propone a cada persona el reto de desarrollar un proyecto personal de vida armónicamente construido sobre la relación consigo misma, con los demás y con Dios. Al proponer la relación con Dios, el escultismo comprende necesariamente que esta relación es recíproca. Dios toma la iniciativa, quiere esa relación y se hace presente en la experiencia educativa de cada scout.

El escultismo católico aporta un nuevo sentido a la propuesta scout, invitando a que el proyecto personal de vida se desarrolle desde la perspectiva completamente nueva que nace del encuentro con Jesucristo.

La vida en el pequeño grupo y en la unidad es la principal vía de participación del niño, niña y joven en la toma de decisiones del movimiento. Los scouts, dependiendo de la edad, trabajan, se organizan y educan según la tabla inferior.

Los marcos simbólicos se han adaptado de acuerdo a la edad psicológica, para que el propio escultismo se convierta en una respuesta real a las inquietudes del momento evolutivo de cada uno:

入 Castores: son la respuesta a una primera experiencia de convivencia fuera de los marcos habituales del niño (familia y escuela esencialmente).

7 Lobatos: responde a la necesidad de establecer comunidades. Los niños inician los procesos de asociación y de autoorganización, generando reglas propias de convivencia para su propia comunidad. Favorece los procesos de socialización en la edad en que el niño despierta ese interés.

$\boldsymbol{\lambda}$ Exploradores: coincide con el momento de la toma de conciencia de las diferencias. Es la etapa del descubrimiento, que conduce al desarrollo de su propia identidad y a la experiencia sobre las identidades ajenas. Ese proceso tiene consecuencias en el descubrimiento de los entornos con una primera mirada analítica.

7 Pioneros: se produce en el momento en que se pone en valor la diferencia, reconociendo que la identidad de cada uno, adecuadamente puesta al servicio de los demás, es la que produce el verdadero impulso a los proyectos. Se avanza por nuevos territorios gracias al valor aportado por cada uno de los participantes en los proyectos. Al mismo tiempo la mirada analítica pasa a ser crítica, lo que favorece la inquietud por generar cambios.

7 Ruta: se corresponde con el momento en que se acentúa notablemente la indi-
Organización scoutpor edad, curso y estudios

\begin{tabular}{|c|c|c|c|c|c|c|c|c|c|c|c|c|c|c|c|c|c|c|}
\hline \multirow{2}{*}{$\begin{array}{l}\text { Rama } \\
\text { Edad }\end{array}$} & \multicolumn{3}{|c|}{ Castores } & \multicolumn{3}{|c|}{ Lobatos } & \multicolumn{3}{|c|}{ Exploradores } & & & & \multicolumn{6}{|c|}{ Rutas } \\
\hline & 6 & 7 & 8 & 9 & 10 & 11 & 12 & 13 & 14 & 15 & 16 & 17 & 18 & 19 & 20 & 21 & 22 & 23 \\
\hline Curso & 1 운 & $2^{\circ}=$ & 30 & 49 & 50 & 69 & 19 & 20 & 3음 & 49 & 19 & 20 & 10 & 29 & 30 & 49 & 50 & 60 \\
\hline Estudios & \multicolumn{6}{|c|}{ Primaria } & \multicolumn{4}{|c|}{ ESO } & \multicolumn{2}{|c|}{ Bachill. } & \multicolumn{4}{|c|}{ Grado } & \multicolumn{2}{|c|}{ Máster } \\
\hline
\end{tabular}




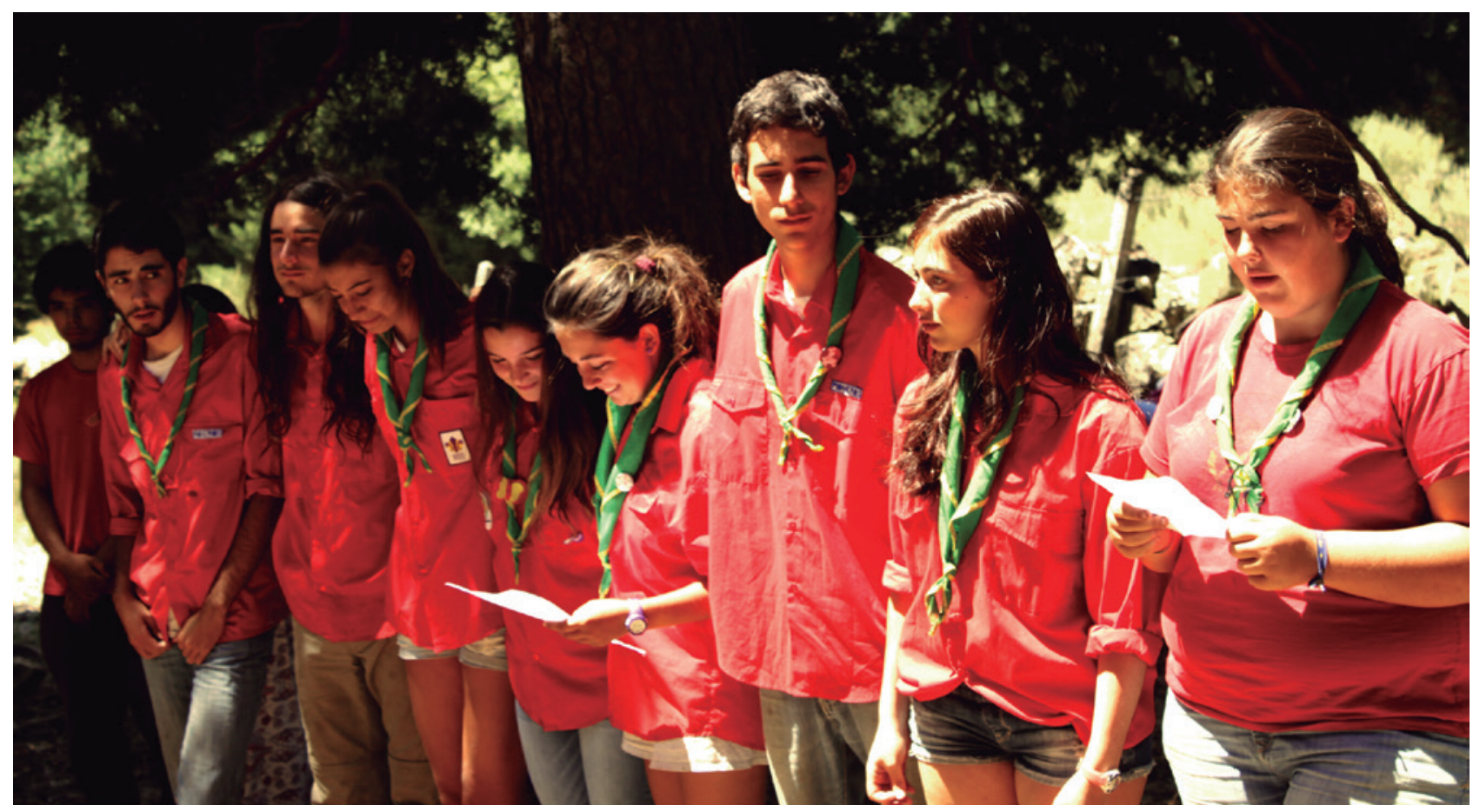

vidualidad, empezando a definirse los caminos personales. La ruta significa el camino que cada uno debe recorrer con independencia, aunque apoyado en sus compañeros, hacia el modelo de vida adulta que el joven piensa como la mejor para él.

El itinerario de progreso personal tiene en cuenta todo lo que ocurre en la vida del scout, tanto dentro del ámbito scout como más allá de la actividad propiamente scout.

En Scouts MSC reconocemos el importante papel que juegan los demás agentes educativos que intervienen en el proceso de crecimiento del scout: padres, madres y tutores, profesores, catequistas, compañeros, entrenadores, orientadores, etc. Es importante fomentar el conocimiento, contacto y coordinación entre el movimiento y todos los agentes que intervienen en los procesos educativos del scout, respetando su intimidad y de acuerdo con el criterio de los padres o tutores.

Es necesario que los padres y tutores sean conscientes de que el movimiento forma parte de la Iglesia y del reflejo que esta pertenencia tiene en la vida del grupo, sin perjuicio de que sus hijos o tutelados puedan formar parte del mismo sin necesidad de ser católicos. Los padres y tutores juegan un papel fundamental a la hora de motivar el progreso personal del scout, facilitando su participación en las actividades scouts y fomentando la coherencia entre la propuesta que le ofrece el movimiento y su vida cotidiana.

\section{El método scout}

Los principios del movimiento scout están fundados en:

入 Deber para con Dios. La adhesión a los principios espirituales, la fidelidad a la religión que los expresa y la aceptación de los deberes que de ellos emanan.

$\boldsymbol{\lambda}$ Deber para con los demás. La lealtad para con su país dentro de la perspectiva de la paz, de la comprensión y la cooperación en el plano local, nacional e internacional. La participación en el desarrollo de la sociedad dentro del respeto a la dignidad del hombre y a la integridad de la naturaleza.

7 Deber para consigo mismo. La responsabilidad de su propio desarrollo.

El escultismo es un juego que tiene como consecuencia el gusto por aprender, por lograr un objetivo, gracias a sus características esenciales: la acción, la imaginación, la aventura, la diversión, la asociación en equipos, el reparto de papeles y el respeto a las reglas pactadas.

El método scout parte de una idea fundamental: confía en que cada persona es capaz de responsabilizarse de su propio desarrollo. Ella es la protagonista del pro- 


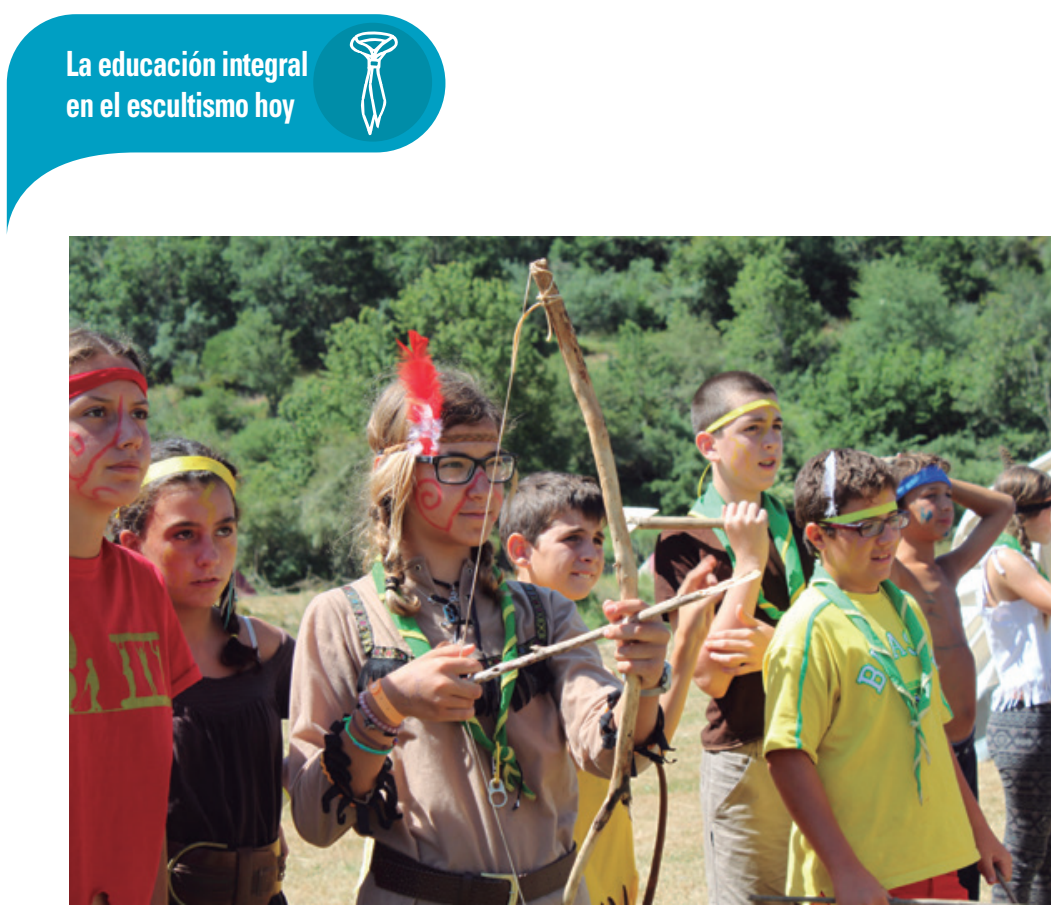

ceso de la educación, el método sólo es el cuadro estructurado que sirve de soporte y de guía. A esta idea de partida la llamamos autoeducación.

\section{Elementos del método}

\section{La Ley y la Promesa}

La Ley scout recoge un conjunto de valores universales que proponen una forma de vida, en una propuesta concreta y pedagógica, que realiza el escultismo, cuya aceptación es necesariamente una libre opción personal. Este compromiso a cumplirlas, público y solemne, es la Promesa scout.

El contenido de la Ley y la Promesa es el mismo en todo el mundo y cada scout lo asume personalmente; de esta forma la Ley y la Promesa constituyen la clave de la unidad ideológica del movimiento scout.

En el escultismo creemos que los principios y objetivos de la educación no deben ser sólo un asunto de las personas adultas; para que los niños y jóvenes se conviertan en responsables de su propio desarrollo dentro del juego scout, es necesario presentarles directamente los objetivos educativos del movimiento en un lenguaje accesible de acuerdo con su edad y deben poder decidir personalmente si se comprometen a esforzarse por alcanzar esos objetivos (ésta es la función metodológica de la Promesa scout).

La Ley y la Promesa son, por constituir su base ideológica, el elemento central del juego scout sobre el que se articulan todos los demás elementos; por ello debe presidir toda la actividad scout, sin limitarse a determinados momentos de carácter más simbólico.

\section{La educación a través de la acción}

En el escultismo se aprende a través de la experiencia y no de una enseñanza teórica: reconocemos el valor de las actividades espontáneas de los niños y jóvenes y confiamos en ellas como motor de la experiencia scout, que se convierte en un sinónimo de acción y de aventura.

El niño o joven es parte activa en todo el proceso, la propuesta, la planificación, ejecución, evaluación y celebración de las acciones. De esta manera las actividades responden de manera efectiva a sus centros de interés. Un niño o joven comprenderá mejor lo que le decimos si lo puede relacionar con una experiencia que ya tiene; las experiencias se hacen significativas en gran medida gracias a la secuencia de reflexión-acción-reflexión.

\section{La vida en pequeños grupos}

El pequeño grupo es una fuente de experiencias que contribuye decisivamente al desarrollo integral de la persona.

En concreto, el juego scout se desarrolla prioritariamente en pequeños grupos porque garantiza la participación, el protagonismo, la asunción de responsabilidades y la corresponsabilidad en el progreso de las personas que integran el grupo de iguales. De esta forma se facilita la interacción positiva de sus integrantes, atendiendo a los intereses y necesidades de todo el mundo y permitiendo la aportación de cada persona al buen funcionamiento del conjunto.

\section{El acompañamiento adulto}

Cada responsable acompaña y ayuda personalmente a cada uno de los niños y jóvenes a jugar al escultismo. Su papel es, sobre todo, el de asegurar que los objetivos educativos del movimiento están presentes para que cada scout pueda progresar extrayendo sus propias conclusiones de las experiencias que vive.

Para ello, orienta, apoya y confía responsabilidades a los niños y jóvenes, asegurándose de que tengan las condiciones adecuadas que necesitan y los medios para desarrollar las actividades que les interesan. 


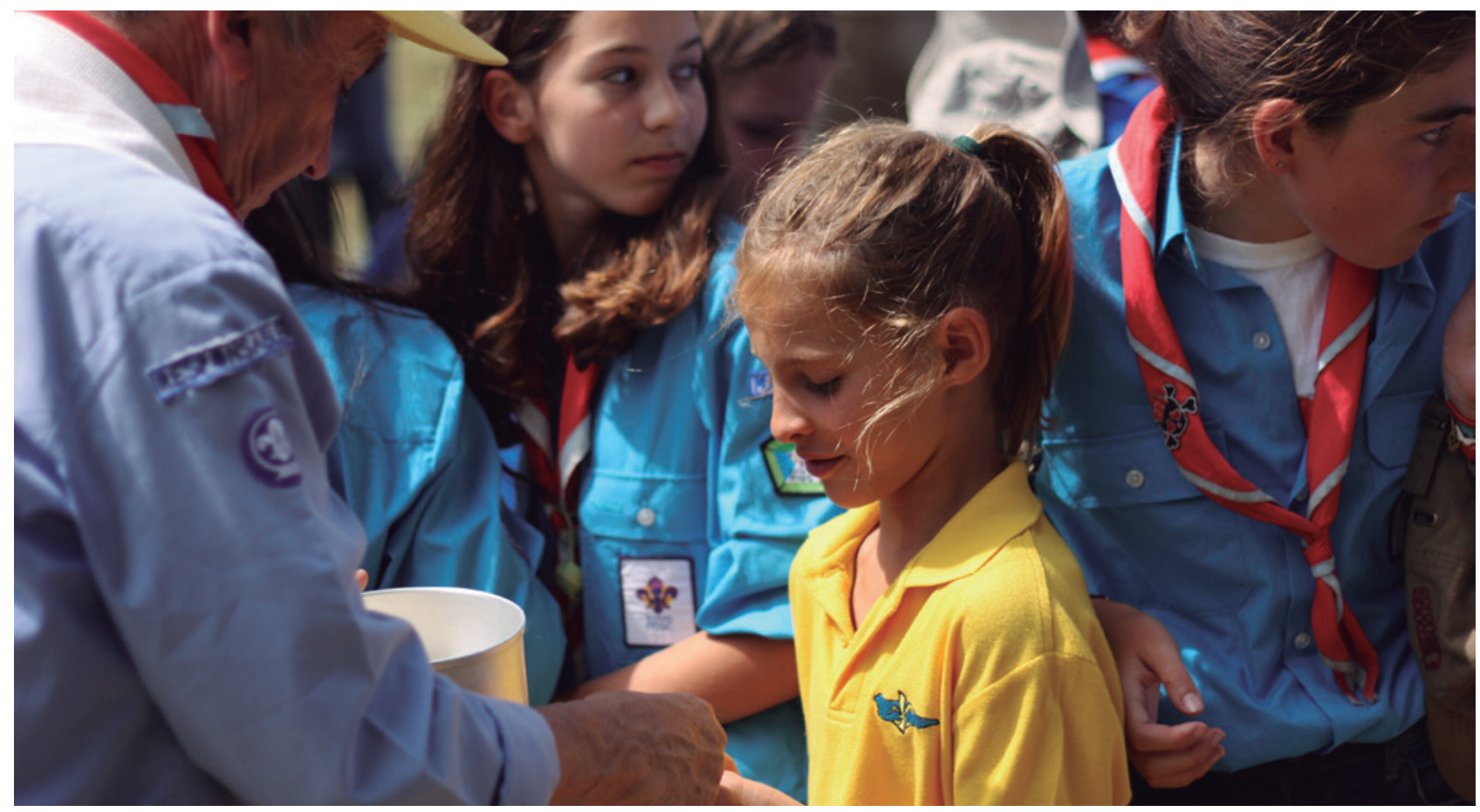

La actividad de la unidad se gestiona conjuntamente entre los niños y jóvenes con las personas adultas que les acompañan: todos toman parte en las decisiones, cada uno desde su rol.

\section{El progreso personal}

El progreso personal en el escultismo, que comienza con la incorporación al movimiento, es el camino recorrido por cada niño y joven para alcanzar los objetivos personales que se han propuesto dentro del marco de objetivos propios de cada rama.

De esta forma, el sistema de progreso personal scout pretende que cada cual, de acuerdo con su edad y características, comprenda los objetivos educativos (qué espera el escultismo de él o ella), elabore su propio plan personal de progreso y vea reconocidos sus esfuerzos, más que los resultados.

Por otra parte, la búsqueda del progreso comunitario estimula el progreso personal de cada miembro del pequeño grupo y unidad. A su vez, la consecuencia del progreso personal de cada scout genera el progreso comunitario.

\section{La vida en la naturaleza}

La naturaleza constituye el marco privilegiado de la actividad scout en todas las ramas y para todas las personas que formamos el movimiento. Es el espacio idóneo para el desarrollo de los sentidos, de las habilidades personales y de la sensibilidad. En ella es más fácil percibir y valorar lo esencial. Es también un medio de socialización, de acercamiento personal y de solidaridad. Permite profundizar en la confianza y adquirir responsabilidad individual y frente al grupo. Es el ambiente más adecuado para descubrir y asumir el lugar del ser humano en el universo, facilitando la apertura a la Trascendencia.

\section{El marco simbólico}

El marco simbólico es el lenguaje propio del movimiento, que permite a todos sus miembros desarrollar una comunicación propia adaptada a cada edad. Este lenguaje da lugar a un sistema de identificación que cohesiona los grupos y refuerza el sentimiento de pertenencia a través de la coherencia en el desarrollo del Programa de Jóvenes.

Está formado por un conjunto de símbolos que representan la propuesta educativa del escultismo: la pañoleta, la flor de lis, los colores de las ramas, las canciones, las tradiciones, las ceremonias... Elementos con significado que ayudan a crear un escenario, una atmósfera que contiene los valores y la propuesta del movimiento, y los hace más accesibles a los niños y jóvenes.

El lenguaje se adapta a cada una de las ramas, partiendo de la creación de "imaginarios" sobre los que desarrollar el juego. Y 


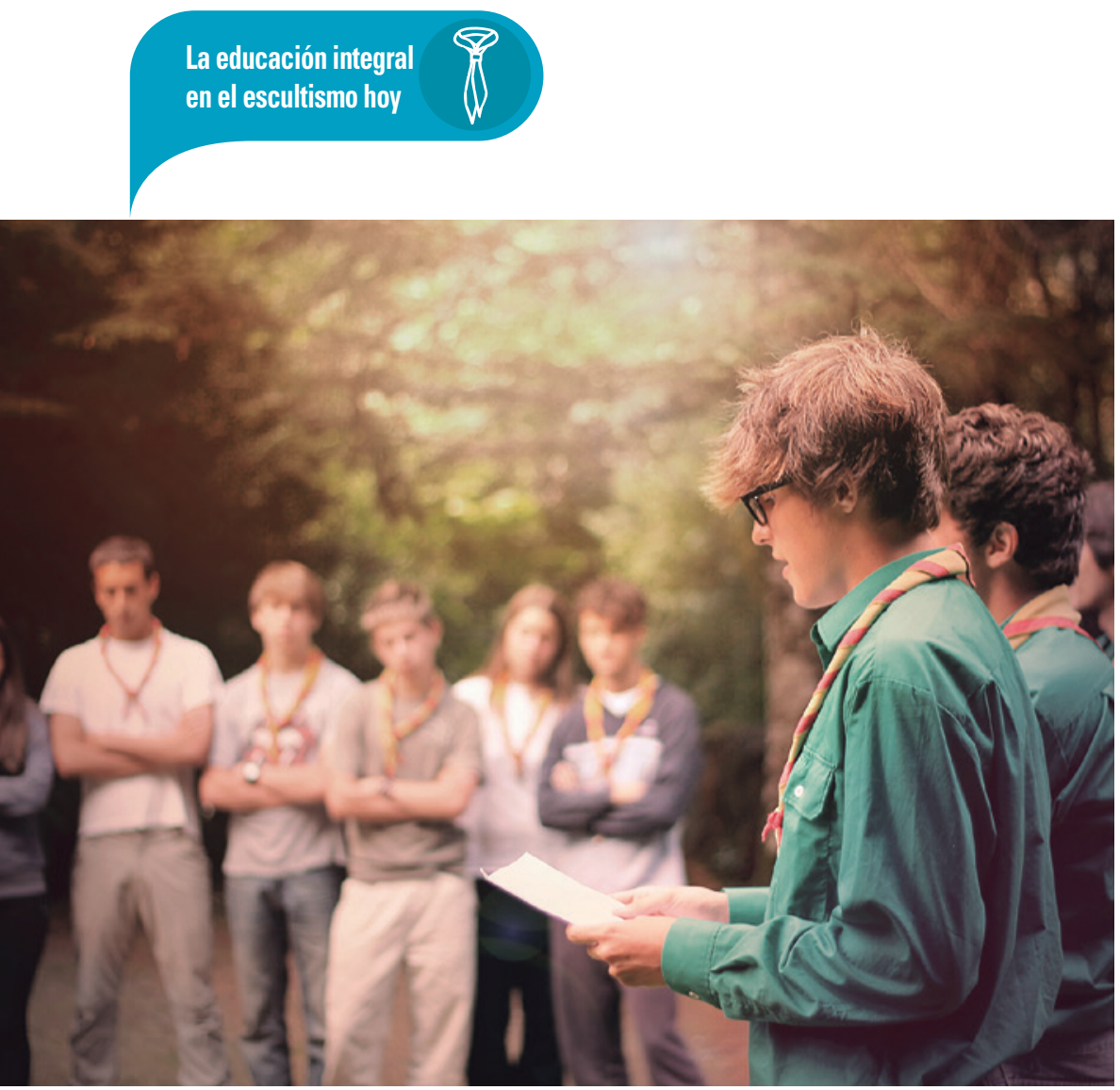

pasando al reto en las edades intermedias (aventura), finalizan en la propia realidad en las etapas de paso a la vida adulta. En todo ello tenemos en cuenta unas áreas mediante las cuales el niño y joven desarrolla y vive todo el recorrido por el escultismo católico, son las siguientes:

خ Área de desarrollo físico: desarrollo de los aspectos de la persona relacionados con el funcionamiento y el desarrollo del cuerpo.

7 Área de desarrollo intelectual: desarrollo de los aspectos de la persona relacionados con la capacidad de per-

\section{(D) PARA SABER MÂS}

Movimiento Scout Católico (ND). Documento de bases del Programa de Jóvenes. Scout.es. Recuperado de http://scouts.es/ media/2013/09/15_10_06-Documento-de-bases-del-Programa-deJovenes-ramas-GS.pdf

Movimiento Scout Católico (2010-2011). El Método Scout. Scout.es. Recuperado de http://scouts.es/media/2015/03/4-el-mc3a9todoscouts-msc2.pdf

Movimiento Scout Católico (2009). Carta Movimiento Scout Católico. Scout.es. Recuperado de http://scouts.es/media/2015/03/1-cartamovimiento-scout-catc3b3lico1.pdf

Movimiento Scout Católico (2009). Las áreas de desarrollo personal en el Programa de Jóvenes Scouts MSC. Scout.es. Recuperado de http:// scouts.es/media/2015/03/2-c3a1reas-desarrollo-scouts-msc1.pdf cibir, pensar, innovar y usar la información de forma original para adaptarse a nuevas situaciones.

7 Área de desarrollo emocional: desarrollo de los aspectos de la persona relacionados con los sentimientos la expresión de los mismos, su equilibrio y su control.

त Área de desarrollo social: desarrollo de los aspectos de la persona relacionados con la interdependencia con los demás y las capacidades de cooperación, liderazgo y servicio.

7 Área de desarrollo espiritual: desarrollo de los aspectos de la persona relacionados con el conocimiento y comprensión de la herencia espiritual de la comunidad y el desarrollo de la relación con Dios, que da sentido a todo, y su repercusión sobre la propia vida, desde el respeto a las demás opciones.

入 Área de desarrollo de la personalidad: desarrollo de los aspectos de la persona relacionados con la responsabilidad con uno mismo y el derecho a desarrollarse, la capacidad de aprendizaje y la búsqueda de la felicidad, la afirmación personal, la capacidad de toma de decisiones, la definición de objetivos personales y el compromiso.

De esta manera Scouts MSC permite trasladar los valores del escultismo a través de un juego hasta la vida real •

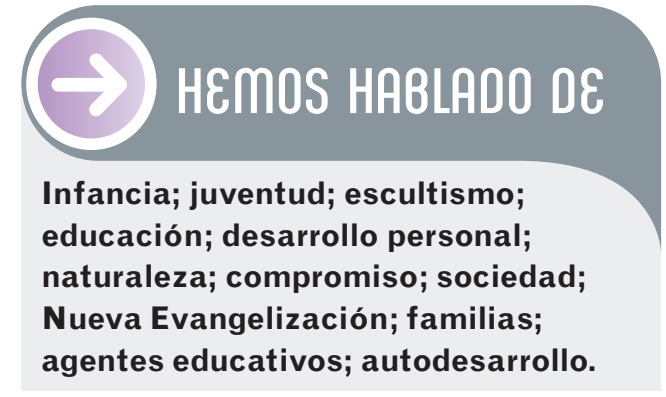

Este artículo fue solicitado por PADRES Y MAESTROS en marzo de 2017, revisado y aceptado en junio de 2017. 


\section{Quieres recibir la newsletter de Padres y Maestros}

Suscribete en nuestra Web y te enterarás antes que nadie de nuestra publicación.

¡Puedes consultar los artículos gratuitamente seis meses después de su publicación en papel!

Además podrás:

$>$ Realizar búsquedas precisas

$>$ Acceder a resúmenes en español y en inglés

$>$ Información detallada sobre los autores

$>$ Extracción de metadatos y citas...
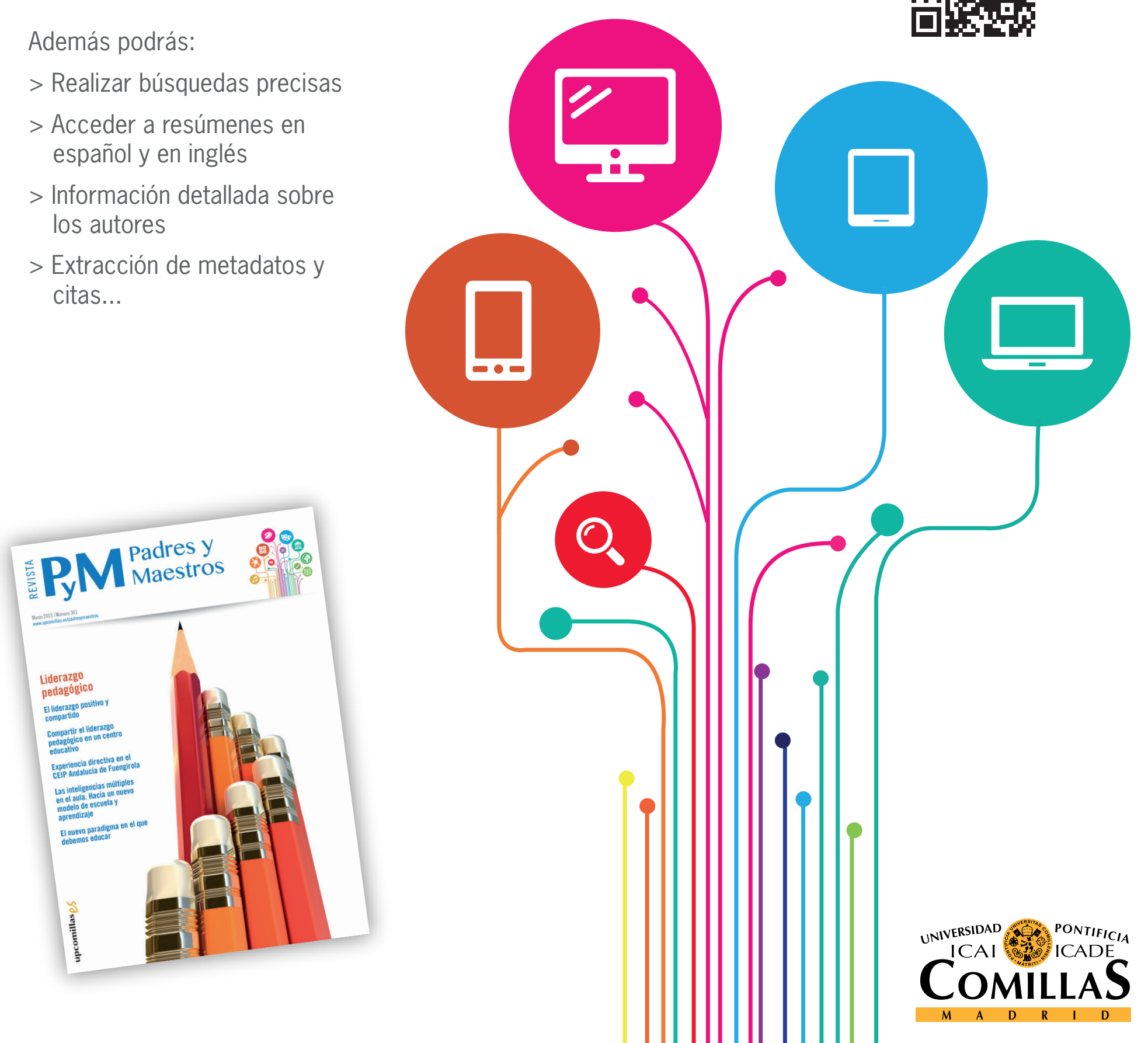